\title{
Management of Behavioural Emergencies: A Prospective Observational Study in Australian
}

\section{Emergency Departments}

Celene YL Yap ${ }^{1,2,3}$, David McD Taylor ${ }^{1,4}$, David CM Kong ${ }^{1,3,5}$, Jonathan C Knott ${ }^{1,2}$, Simone E Taylor $^{6}$, Andis Graudins ${ }^{7,8}$,Gerben Keijzers ${ }^{9,10,11}$,Sanjeewa Kulawickrama ${ }^{9}$, Ogilvie Thom ${ }^{12}$, Luke Lawton $^{13}$, Jeremy Furyk ${ }^{13}$, Daniel Finucci ${ }^{14}$, Anna Holdgate ${ }^{14}$, Gina Watkins ${ }^{15}$, Peter Jordan ${ }^{16}$

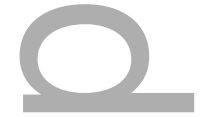

1. Faculty of Medicine, Dentistry and Health Sciences, University of Melbourne, Parkville, Australia

2. Emergency Department, The Royal Melbourne Hospital, Parkville, Australia

3. Centre for Medicine Use and Safety, Monash University, Parkville, Australia

4. Emergency Department, Austin Health, Heidelberg, Australia

5. Pharmacy Department, Ballarat Health Services, Ballarat, Australia

6. Pharmacy Department, Austin Health, Heidelberg, Australia

7. Emergency Department, Monash Health, Clayton, Australia

8. Department of Medicine, Clinical Sciences at Monash Health, Monash University, Clayton, Australia

9. Emergency Department, Gold Coast University Hospital, Southport, Australia

10. School of Medicine, Bond University, Gold Coast, Australia

11. School of Medicine, Griffith University, Gold Coast, Australia

12. Emergency Department, Nambour General Hospital, Nambour, Australia

13. Emergency Department, The Townsville Hospital, Townsville, Australia

14. Emergency Department, Liverpool Hospital, Liverpool, Australia

15. Emergency Department; Sutherland Hospital, Caringbah, Australia

16. Emergency Department, The Northern Hospital, Epping, Australia

\section{Authors:}

Dr Celene YL YAP

BPharm, MSc in Clinical Pharmacy, International Policy and Practice, BCPS, PhD

Research Fellow. Faculty of Medicine, Dentistry and Health Sciences,

This is the author manuscript accepted for publication and has undergone full peer review but has not been through the copyediting, typesetting, pagination and proofreading process, which may lead to differences between this version and the Version of Record. Please cite this article as doi: 10.1002/jppr.1522

This article is protected by copyright. All rights reserved 
The University of Melbourne, Victoria 3010, Australia.

yen.yap@unimelb.edu.au

Prof David McD TAYLOR

MBBS, MD, MPH, DRCOG, FACEM

Director of Emergency Medicine Research. Emergency Department, Austin Health, Studley Road, Heidelberg, Victoria 3084, Australia

David.Taylor@austin.org.au

\section{Dr David CM KONG}

BPharm, MPharm, PhD

Deputy Director of Pharmacy. Pharmacy Department, Ballarat Health Services, 1 Drummond St N, Ballarat Central, Victoria 3350, Australia.

David.Kong@monash.edu

A/Prof Jonathan C KNOTT

MBBS, Grad Dip Epi Biostats, PhD, FACEM

Director of Emergency Research. Emergency Department, The Royal Melbourne Hospital, 300 Grattan Street, Parkville, Victoria 3050, Australia

Jonathan.Knott@mh.org.au

Dr Simone E TAYLOR

BPharm, PharmD

Senior Pharmacist. Pharmacy Department, Austin Health, Studley Road, Heidelberg, Victoria 3084, Australia

Simone.Taylor@austin.org.au

Prof Andis GRAUDINS

MBBS (Hons), PhD, FACEM, FACMT

Director of Monash Health Emergency Medicine and Clinical Toxicology Research Unit. Monash Health, David Street, Dandenong VIC 3175, Australia.

Andis.Graudins@monash.edu

\section{Prof Gerben KEIJZERS}

MSc (Biomed Health Sci), MBBS, FACEM, PhD

This article is protected by copyright. All rights reserved 
Senior Staff Specialist. Emergency Department, Gold Coast University Hospital, 1 Hospital Boulevard, Southport, QLD 4215, Australia.

Gerben.Keijzers@health.qld.gov.au

Dr Sanjeewa KULAWICKRAMA

MBBS, FACEM

Emergency Physician. Emergency Department, Gold Coast University Hospital, 1 Hospital Boulevard, Southport, QLD 4215, Australia.

Sanjeewa.Kulawickrama@health.qld.gov.au

Dr Ogilvie THOM

MBBS, FACEM

Emergency Physician. Emergency Department, Nambour General Hospital, Hospital Road, Nambour

QLD 4560, Australia.

ontho25@gmail.com

Dr Luke LAWTON

BApp Sc (Biochemistry) MBBS (Hons), MPH (Aeromedical Retrieval) FACEM

Deputy Director of Emergency Medicine, Emergency Department, The Townsville Hospital, IMB 23, PO Box 670, Townsville QLD 4810, Australia.

Luke.Lawton@health.qld.gov.au

Dr Jeremy FURYK

MBBS, FACEM

Senior Staff Specialist. Emergency Department, The Townsville Hospital, IMB 23, PO Box 670, Townsville QLD 4810, Australia.

Jeremy.Furyk@health.qld.gov.au

Dr Daniel P FINUCCI

MBBS, MMedSci, FACEM

Emergency Physician. Emergency Department, Liverpool Hospital, Locked Bag 7103 Liverpool BC, NSW 1871, Australia.

Daniel.Finucci@sswahs.nsw.gov.au

This article is protected by copyright. All rights reserved 
A/Prof Anna HOLDGATE

MBBS, FACEM, MMed

Director, Emergency Medicine Research Unit, Emergency Department, Liverpool Hospital, Locked Bag 7103 Liverpool BC NSW 1871, Australia.

anna.holdgate@swsahs.nsw.gov.au

Dr Gina WATKINS

MBBS, FACEM

Senior Emergency Physician. Emergency Department, Sutherland Hospital, Locked Bag 21, Taren

Point, NSW 2229, Australia.

Gina.Watkins@sesiahs.health.nsw.gov.au

Dr Peter JORDAN

MBBS, FACEM

Director of Emergency Medicine. Emergency Department, Northern Health, 185 Cooper Street, Epping VIC 3076, Australia.

Peter.jordan@nh.org.au

Address for correspondence:

Dr David CM KONG

Deputy Director of Pharmacy. Pharmacy Department,

Ballarat Health Services,

1 Drummond St N, Ballarat Central, Victoria 3350, Australia;

David.Kong@monash.edu

Phone: +61353204106

Fax: +6135320 4109

Running title: sedation practice for behavioural emergencies

\section{Author contributions:}

CY, DK, DT, ST and JK conceived and participated in designing the study. CY and DT undertook the data analysis. All authors contributed to data collection, interpretation of the This article is protected by copyright. All rights reserved 
results, drafting and revision of the manuscript. All authors take responsibility for the paper as a whole.

Head of department submission confirmation: Approvals for this manuscript to be published were obtained from the head of emergency department for the ten participating hospitals.

Human studies statement: Ethical approvals and site specific authorisations were obtained from the participating hospitals. Patient consent was waived as this study was purely observational and with no approach to or collection of data from the patients

Conflicts of interest: All authors report no conflict of interest.

Funding source: SHPA Emergency Medicine Grant 2014 (EME 1402), Emergency Medicine Foundation (EMTR-101R23-2015)

\section{Acknowledgement:}

The authors would like to acknowledge the co-operation and support provided by the staff of the participating emergency department.

The study was supported by:

- SHPA Emergency Medicine Grant 2014 (EME 1402)

- Emergency Medicine Foundation (EMTR-101R23-2015)

The funding organisations did not have any role in the design or execution of the study, data analysis or interpretation.

Word count: Abstract 240, Text 2989

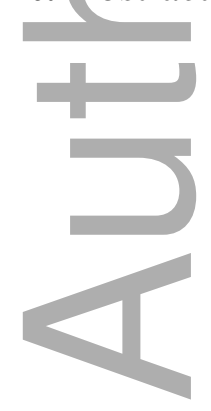

This article is protected by copyright. All rights reserved 
DR. CELENE YL YAP (Orcid ID : 0000-0001-8359-0605)

Article type : Research Article

Management of Behavioural Emergencies: A Prospective Observational Study in Australian

Emergency Departments

10 Abstract

$11 \quad$ Aim

12 To describe the prescribing patterns and adverse events (AEs) associated with parenteral sedation

13 for the management of behavioural emergencies (BEs) in Australian emergency departments (EDs).

14 Methods

15 Ten Australian EDs enrolled a convenience sample of adult patients (aged 18 years or more) 16 requiring parenteral sedative medication for BEs. Data were collected prospectively between March 172015 and April 2017 using a designated case report form.

\section{Results}

19 A total of 564 cases were enrolled. Incomplete cases (17 cases, 3\%) were excluded. Of the 547 20 remaining cases, 63\% were male and the median age was 34 years (range 18 to 95 years). 21 Approximately one half $(230,42.1 \%)$ of patients required mechanical restraint and parenteral sedation to manage their BEs. Intramuscular monotherapy was administered in most cases (390,

23 71.3\%). The main sedative medications used as monotherapy were droperidol (381, 69.7\%), 24 midazolam $(54,9.9 \%)$ and olanzapine $(26,4.8 \%$,). The most common combination therapy was 25 midazolam + droperidol $(36,6.6 \%)$. The AE incidence from sedative administration was $13.5 \%$. No 26 death or irreversible AEs were reported.

\section{Conclusions}

28 Overall, the participating EDs provided safe pharmacological management for BEs. Adverse events 29 following parenteral sedation are common although serious AEs are rare. As all patients receiving 
parenteral sedation for BEs are at risk for AEs, ongoing monitoring of vital signs after parenteral

31 sedation should be a standard protocol in all EDs.

\section{Keywords}

33 Behavioural emergencies, agitation, sedatives, parenteral sedation, adverse events, emergency department, prescribing patterns, monotherapy, combination therapy, antipsychotics, benzodiazepines.

Introduction

Patients with behavioural emergencies (BEs) commonly present to emergency departments (EDs), with staff frequently exposed to violent and aggressive behaviours. Australian studies have revealed that the majority of clinical staff working in the ED experience some form of violence at least weekly, ${ }^{1}$ and in a recent study, an increasing trend in the incidence of violence was reported. ${ }^{2}$ Behavioural emergencies are challenging to manage due to the need to make quick treatment decisions for patients unable to provide an accurate clinical history at presentation.

Current guidelines recommend managing BEs initially with oral sedative medications whenever possible. ${ }^{3,4}$ This recommendation is based on expert opinion and consumer surveys which indicate that oral medication administration is less coercive and is perceived as less traumatic by psychiatric patients. However, there is a subset of agitated patients for whom parenteral sedation is the only feasible option. In a study by Hatta et al. ${ }^{5}$ more than one half of eligible patients $(118 / 208,57 \%)$ refused oral medications and required management with parenteral sedation. Consequently, parenteral sedation has an important role in the management of BEs in EDs, especially for patients with severe agitation or patients who refuse oral medications.

Parenteral sedation for the management of BEs in the ED has typically involved the use of benzodiazepines, and antipsychotics. ${ }^{4,6}$ Whilst monotherapies have been commonly used, several studies have shown that combination therapies provide significantly more rapid and effective sedation. ${ }^{7-9}$ Other parenteral sedative medications such as ketamine have also been investigated for severely agitated patients in the ED. ${ }^{10}$ It is unknown whether the publication of new evidence has translated into changes in prescribing patterns. 
61 Patients presenting with BEs can be highly complex with co-morbid medical and substance abuse 62 issues. Randomised controlled trials (RCTs) that investigated the safety and efficacy of parenteral 63 sedation for BEs management suggest that adverse events (AEs) are common. ${ }^{11}$ However, due to safety and ethical reasons, certain patient groups (e.g. patients aged above 65 years) are commonly excluded from RCTs. Given the limitations of RCTs, data on AEs from observational studies can complement RCT data.

The aim of this paper is to describe the prescribing patterns and AEs associated with parenteral sedation for the management of BEs in Australian EDs.

\section{Method}

\section{Study Design and Study Population}

This was a multi-centre prospective observational study undertaken in the EDs of ten Australian public, tertiary-referral hospitals across three states (i.e. Victoria [VIC], Queensland [QLD] and New South Wales [NSW) in Australia from March 2015 to April 2017. The annual patient census of these EDs ranged from 50,000 to 100,000 patients. Each ED is supported by 24-hour co-located psychiatric services. Ethical Committee approvals and site-specific authorisations were obtained from all the study sites. Due to the level of agitation during a BE, informed consent was not possible and waiver of consent was granted.

A convenience sample of patients aged 18 years or older and who required parenteral sedation for BE was enrolled at the participating EDs. There were no exclusion criteria. All participants were managed according to usual clinical practice and local hospital guidelines. The choice of parenteral sedation was entirely at the discretion of the treating doctor and was not stipulated by recruitment into the study. After sedation had been achieved, regular observations including pulse, respiratory rate, airway patency, skin colour, blood pressure and oxygen saturation were undertaken at least every 10-15 minutes for one hour.

\section{Data Collection}

Data were collected using a designated case report form. The occurrence of respiratory AEs (i.e. hypoventilation [respiratory rate $<10$ breaths/min], oxygen desaturation [oxygen saturation $<90 \%$ $\mathrm{mmHg}$ ], partial or complete airway obstruction); cardiovascular AEs (i.e. prolonged QTc [corrected This article is protected by copyright. All rights reserved 
QT $>500 \mathrm{~ms}$ ], tachycardia [heart rate $>100$ beats per minute], bradycardia [heart rate $<60$ beats per minute); and other AEs (i.e. extrapyramidal side effects [EPSE], vomiting, anticholinergic side effects [e.g. urinary retention, dry mouth], fall and anaphylaxis) were recorded by the ED staff as soon as they occurred. Outcome of the reported AE was reported as not resolved, resolved or resolved with sequelae. A serious $\mathrm{AE}$ was defined as death, life-threatening (e.g. respiratory arrest), or requiring hospitalisation (i.e. admission to medical wards or intensive care units due to the AE), or if deemed to have caused persistent disability.

Patient demographic, baseline characteristics data and information on parenteral sedation prescribed in the ED including name, dose, route and time of administration were collected retrospectively from the medical records by site investigators. For this study, combination therapy was defined as two different types of sedative medications administered within 15 minutes of each other.

\section{Data Analysis}

Two clinical trials investigating the management of BE in EDs reported that AEs occurred in $11.6 \%^{9}$ and $13.7 \%^{12}$ of patients. Our sample size was initially calculated to be at least 1944 patients in order to be $95 \%$ certain that the $\mathrm{AE}$ rate would range between $11 \%$ and $14 \%$ (level of significance 0.05). An interim analysis was conducted at the two-year point of the study, and because of the AE rate had reached $13.5 \%$, (within the estimated range), the study was concluded.

Patient demographics, prescribing patterns, nature and frequency of AEs were analysed descriptively and reported as frequencies and percentages. Categorical variables were compared using the chi-square test or Fisher's exact test, as appropriate. Medians are reported with ranges or interquartile ranges (IQRs) for continuous variables. Subgroup analysis for patients aged above 65 years was performed to examine parenteral sedation practice of elderly patients with BEs in the ED. All analyses were performed using IBM SPSS Statistics Version 24 (Armonk. NY: IBM Corp.). The level of significance was 0.05 .

\section{Results}

\section{Description of the presentations}

The study was concluded at the two-year point with 564 cases enrolled. Seventeen cases were excluded due to incomplete information. Of the remaining 547 cases, there were 27 (4.9\%) cases 
124 from two EDs in NSW, 222 (40.6\%) cases from five EDs in VIC, and 298 (54.5\%) cases from three 125 EDs in QLD.

\section{Patient characteristics}

128 A summary of the patient characteristics by initial choice of sedation regimens is reported in Table 129 1. Overall, there was a high prevalence of either alcohol or illicit drugs usage (or both). Among the 130236 patients identified as ingesting alcohol prior to ED presentation, 19.5\% (46/236, [95\%) had 131 blood alcohol concentrations documented. The mean (SD) blood alcohol concentration among these 132 patients was $0.198(0.1) \mathrm{g} / \mathrm{dL}$. Of the 247 patients who admitted to using illicit drugs before the 133 presentation, almost one half (106/247, [42.9\%) reported methamphetamine use. Other illicit drugs 134 that were used by these patients including cannabis (38/247, [15.4\%, ecstasy (11/247, [4.5\%), and 135 gamma hydroxybutyrate (6/247, [2.4\%). Polysubstance misuse was common; 113 (20.7\%) patients 136 had used both alcohol and illicit drugs, and 47 (8.6\%) patients had used more than one type of illicit 137 drug prior to the presentation.

139 Patients who received monotherapy or combination parenteral sedation therapy were of similar age 140 and gender. However, more patients in the combination group had a final diagnosis of substance 141 intoxication. Significantly more patients in the combination group were affected by illicit drugs 142 (Table 1). Although the need for mechanical restraint was greater among patients in the 143 combination group, the difference between those receiving monotherapy and combination 144 parenteral sedation therapy was not statistically significant.

\section{Initial choice of parenteral sedation}

147 The initial choice of parenteral sedation, by route of administration, is described in Table 2. 148 Overall, monotherapy was more commonly administered than combination therapy. The 149 intramuscular (IM) route was preferred over intravenous (IV) route. However, NSW reported a 150 significantly higher number of cases (33.3\%) using IV route to administer monotherapy than VIC 151 (8.0\%) and QLD (22.4\%).

153 Overall, the main sedative medications used as monotherapy were droperidol, midazolam and 154 olanzapine. No significant difference was observed in the proportion of patients sedated with 155 droperidol monotherapy among the three states $(\mathrm{p}>0.05)$. However, significantly more patients in 
VIC (11.7\% vs $1.5 \%$ in QLD and $0 \%$ in NSW) were sedated with olanzapine monotherapy (p $<0.001)$; and significantly more patients in NSW (33.3\% vs 5.3\% in VIC and $14.7 \%$ in QLD) were sedated with midazolam monotherapy $(\mathrm{p}<0.001)$.

Droperidol, alone or in combination, was used in more than two-thirds of all cases $(381 / 547$; $69.7 \%$ ), with IM droperidol 10mg being the most frequently prescribed regimen $(293 / 547 ; 53.6 \%)$. When combination therapy was administered, droperidol was combined with midazolam more frequently than with other sedative medications. No significant differences were observed in the choice of combination therapy between the states, except the combination of droperidol and olanzapine, where all eight cases were reported by the participating EDs in VIC.

\section{Adverse events}

168 A total of 82 AEs was identified among 74 patients. The incidence of AE at the two-year point was $16913.5 \%$ (74/547), within the estimated range. Table 3 describes the frequency and nature of AEs.

170 Respiratory AEs included oxygen desaturation, airway obstruction and hypoventilation were the most commonly reported AEs. All respiratory AEs were managed with the administration of oxygen, airway positioning, or bag-mask ventilation. No patient in this study required endotracheal intubation secondary to parenteral sedation, and no reversal drugs (e.g. flumazenil) were administered. One patient experienced anaphylaxis (attributed to droperidol) which resolved after a single dose of IM adrenaline. All other reported AEs were transient and resolved without adverse clinical outcomes. No deaths or other serious AEs were reported.

179 There were 31 patients aged above 65 years and the median age of this subgroup was 81 years (IQR $18075-87$ years). The majority of this subgroup of patients were male $(23 / 31 ; 74.2 \%)$. Among these, the 181 main comorbidities associated with the BEs were dementia $(11 / 31 ; 35.5 \%)$, alcohol intoxication $182(3 / 31 ; 9.7 \%)$, and urosepsis $(2 / 31 ; 6.5 \%)$. Monotherapy was administered in nearly all cases (Table 183 4). The main sedative medications used as monotherapy in this subgroup of patients were 184 droperidol, olanzapine, midazolam and haloperidol. oxygen desaturation $(3 / 31 ; 9.7 \%)$, bradycardia $(2 / 31 ; 6.5 \%)$, anticholinergic side effects (i.e. dry 
mouth, difficulty urinating) $(2 / 31 ; 6.5 \%)$, QTc prolongation $(1 / 31 ; 3.2 \%)$, and tachycardia $(1 / 31$; 3.2\%). All AEs reported in this subgroup of patients were resolved without adverse clinical outcomes.

\section{Discussion}

To our knowledge, this is the largest prospective observational study of $\mathrm{BE}$ management in Australian EDs and it has provided pivotal insight into current clinical practice. Our study demonstrates that droperidol is the most common monotherapy prescribed for the management of acute agitation in Australia. This differs from other countries, where haloperidol is the first choice for sedation of acutely agitated patients in the United States of America (USA), ${ }^{6}$ the United Kingdom, ${ }^{13}$ Europe ${ }^{14}$ and Hong Kong. ${ }^{15}$ This difference might relate to the limited availability of droperidol in these countries. In 2001, a black-box warning was issued for droperidol by the USA Food and Drug Administration because of a risk of development of torsade de pointes induced by QT prolongation. ${ }^{16}$

Our findings demonstrate a noticeable change in the prescribing pattern for the management of $\mathrm{BE}$ in the Australian setting. In a survey conducted in 2009, midazolam was reported as the most preferred choice of parenteral sedation for agitation management among Australasian College of Emergency Medicine members, ${ }^{17}$ and it is the first-line therapy recommended in the Therapeutic Guidelines for behavioural emergencies. ${ }^{4}$ The increasing number of studies documenting efficacy and safety of droperidol in the Australian ED setting in the last five years, ${ }^{9}, 18,19$ may have reduced markedly the preference for midazolam. Furthermore, the publication of state health policies from both $\mathrm{NSW}^{20}$ and $\mathrm{QLD}^{21}$ in 2015 may also have contributed to the observed changes in the prescribing pattern. In our study, droperidol 10mg was the most commonly prescribed dose, which is consistent with the dose used in several clinical studies. ${ }^{7,12,19,22}$ Whilst emerging data from observational studies show that ketamine appears to be effective in managing severely agitated patients, ${ }^{10}$ it was not commonly used in the participating EDs.

The cause of BEs is often multifactorial. Patients may present with (i) acute psychosis (e.g. first episode of psychosis or with underlying mental illness) with no detectable underlying medical disease; (ii) dual diagnosis (i.e. individuals with both psychiatric and substance use disorders); (iii) acute psychosocial crises (e.g. suicidal, deliberate self-harm); (iv) substance intoxication or withdrawal (e.g. simple alcohol intoxication, methamphetamine overdose.); or (v) organic disorders 
221 without underlying psychiatric disorders (e.g. hypoglycaemia, hyperthyroidism). ${ }^{4}$ Our study shows 222 that more patients with a final diagnosis of substance intoxication required parenteral sedation for 223 BEs than those with a final diagnosis of mental illness. This suggests that patients intoxicated with 224 either alcohol and/or illicit substances may not respond adequately to non-pharmacological 225 interventions (e.g. verbal de-escalation) and may not accept oral medications. Further studies 226 investigating the efficacy and safety of various parenteral sedation regimens for the management of 227 illicit substances-related agitation in the ED are required to ensure optimal management of this 228 subgroup of patients.

230 Although most of our patients were managed with monotherapy, it is notable that a wide variety of 231 sedative combinations are used, albeit in small numbers. Whilst there is high-quality evidence that 232 supports the efficacy advantage of adding a benzodiazepine to an antipsychotic, ${ }^{8}$ the use of two 233 antipsychotics e.g. droperidol and olanzapine has not been well studied. As droperidol and 234 olanzapine both have anticholinergic effects and increase the risk of seizures, the concurrent use of 235 these two antipsychotics may increase the risk of AEs, which include central anticholinergic 236 delirium. $^{23}$ Hence, these combinations should be used with caution. The practice of 237 'experimentation' with different sedative medications highlights the need to develop and to promote 238 the use of a standardised guideline for the management BEs in VIC. We did not specifically collect 239 data on the rationale for combination parenteral sedation therapy and as such cannot comment on 240 the individual clinicians' choice.

242 Our findings that respiratory AEs were the most common AEs are consistent with previous RCTs of 243 different sedative medications in the management of acute agitation. ${ }^{7,}$, 12,22 Given the transient 244 nature of most respiratory AEs, it is possible that some of the respiratory events were not recorded. 245 The frequency of these AEs, and their transient nature, highlight the need for meticulous observation and monitoring to prevent a relatively minor $\mathrm{AE}$ becoming a serious $\mathrm{AE}$. Patients 248 forget" medication orders. These patients must be cared for, in monitored and high visibility areas of the ED, by staff with expertise in airway management.

251 Given the large number of elderly patients (i.e. >65 years) who present to EDs, this group was 252 underrepresented in this study. This suggests that parenteral sedation may not be widely used in this 253 population. This result is consistent with current best practice recommendations. ${ }^{3,4}$ Also consistent 
with previous literature, organic disorders, such as underlying dementia were found to be the most common diagnosis in elderly patients who required parenteral sedation. ${ }^{24}$ In line with previous studies, lower doses of parenteral sedation were administered to the elderly patients with BEs. ${ }^{25}$ However, there was a marked variation in the choice of initial sedative medication. Although not quite reaching statistical significance there was a trend towards AEs being more prevalent in patients aged $>65$ years compared to patients aged $<65(8 / 31 ; 25.8 \%$ versus $66 / 516 ; 12.8 \% ; p$ $=0.0544)$.

Given the vulnerability of elderly patients to AEs, our findings support the need to monitor these patients carefully following parenteral sedation. A larger study examining the use of parenteral sedation among elderly patients will be required to determine the incidence and risk factors (e.g. polypharmacy) that are associated with sedation-induced AEs.

There are limitations in the generalisability of our data. Although these data are not necessarily representative of the practice Australia-wide, they provide unique insights into prescribing patterns for the management of BEs. Although every effort was made to encourage clinical staff to enrol eligible patients into the study, the busy nature of EDs makes it challenging for all clinical staff to stay committed to the process of patient recruitment. Patients may have been missed and had no data collected, resulting in a truly consecutive sample not being achieved and selection bias might have been introduced. It was also not possible to retrospectively determine the number and nature of the patients not enrolled as sedation for management of acute agitation is not specifically classified in medical records. In addition, some minor AEs may not have been recorded. Whilst higher sample numbers will lead to smaller confidence intervals and increase the chance of detecting rare AEs, the current sample size which afforded $13.5 \%$ AEs is within the estimated range and appears to have captured the most common types of AE related to the parenteral sedation in this setting.

Other limitations of this study include those associated with observational studies such as the absence of randomisation and blinding. However, the naturalistic design of this multicentre observational study provides a clear description of current parenteral sedation practice in the participating EDs and enables assessment of AEs in a broad group of patients (e.g. inclusive of elderly patients). This study sought to document AEs associated with parenteral sedation but cannot make recommendations regarding the dose-response relationship between specific sedative medications and AEs. 


\section{Conclusion}

288 Overall, the participating EDs provided safe pharmacological management for BEs. The current 289 findings suggest the parenteral sedation practice has changed in accordance with the emerging new 290 evidence from clinical studies. As all patients receiving parenteral sedation for BEs are at risk for 291 AEs, ongoing monitoring of vital signs after parenteral sedation should be a standard protocol in all 292 EDs.

294 Table 1. Characteristics of participants

\begin{tabular}{|c|c|c|c|c|}
\hline & $\begin{array}{c}\text { Total } \\
(n=547)\end{array}$ & $\begin{array}{l}\text { Monotherapy } \\
\qquad(\mathrm{n}=472)\end{array}$ & $\begin{array}{c}\text { Combination } \\
\text { therapy } \\
(n=75)\end{array}$ & $P$ value \\
\hline Age, years & & & & 0.78 \\
\hline$\leq 30$ & $188(34.3)$ & $161(34.1)$ & $27(36.0)$ & \\
\hline $31-65$ & $328(60.0)$ & $283(60.0)$ & $45(60.0)$ & \\
\hline$>65$ & $31(5.7)$ & $28(5.9)$ & $3(4.0)$ & \\
\hline Male, n (\%) & $346(63.3)$ & $298(63.1)$ & $48(64.0)$ & 0.89 \\
\hline ICD-10 category, $\mathrm{n}(\%)$ & & & & 0.31 \\
\hline Mental illness & $216(39.5)$ & $190(40.3)$ & $26(34.7)$ & \\
\hline Intoxication (drugs and/or alcohol) & $263(48.1)$ & $221(46.8)$ & $42(56.0)$ & \\
\hline Organic illness & $68(12.4)$ & $61(12.9)$ & $7(9.3)$ & \\
\hline Drug overdose at presentation & $49(9.0)$ & $46(9.7)$ & $3(4.0)$ & 0.11 \\
\hline $\begin{array}{l}\text { Usual psychotropie medications } \\
\text { prior to presentation, n (\%) }\end{array}$ & $211(38.6)$ & $187(39.6)$ & $24(32.0)$ & 0.21 \\
\hline Benzodiazepines & $73(13.3)$ & $65(13.8)$ & $8(10.7)$ & 0.46 \\
\hline SSRI or SNRI & $65(11.9)$ & $56(11.9)$ & $9(12.0)$ & 0.97 \\
\hline Atypical antipsychotics & 109 (19.9) & $95(20.1)$ & $14(18.7)$ & 0.77 \\
\hline
\end{tabular}




\begin{tabular}{|c|c|c|c|c|}
\hline & $\begin{array}{c}\text { Total } \\
(\mathrm{n}=547)\end{array}$ & $\begin{array}{l}\text { Monotherapy } \\
(n=472)\end{array}$ & $\begin{array}{l}\text { Combination } \\
\text { therapy } \\
(\mathbf{n}=75)\end{array}$ & $P$ value \\
\hline Typical antipsychotics & $14(2.6)$ & $13(2.8)$ & $1(1.3)$ & 0.71 \\
\hline Prescription opioids* & $57(10.4)$ & $53(11.2)$ & $4(5.3)$ & 0.12 \\
\hline Alcohol intoxicated, $\mathrm{n}(\%)$ & $236(43.1)$ & $206(43.6)$ & $30(40.0)$ & 0.55 \\
\hline Illicit drug intoxicated, n (\%) & $247(45.2)$ & $204(43.2)$ & $43(57.3)$ & 0.02 \\
\hline Need for mechanical restraint, n (\%) & $230(42.0)$ & $192(40.7)$ & $38(50.7)$ & 0.10 \\
\hline $\begin{array}{l}\text { Need for additional parenteral } \\
\text { sedation within the first } 60 \text { minutes } \\
\text { after the initial dose regimen, } \mathrm{n}(\%)\end{array}$ & $71(13.0)$ & $62(13.1)$ & $9(12.0)$ & 0.79 \\
\hline
\end{tabular}

ICD-10=International Classification of Diseases; SSRI=selective serotonin reuptake inhibitor; SNRI=serotonin noradrenalin-reuptake inhibitor

297 *Prescription opioids included oxycodone, hydrocodone, morphine, codeine, fentanyl, methadone, hydromorphone

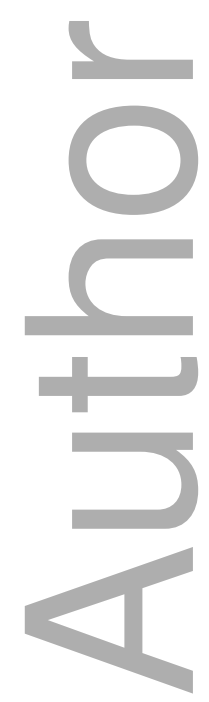


Table 2. Initial choice of sedation regimens for all patients

\begin{tabular}{|c|c|c|c|c|}
\hline \multirow[t]{2}{*}{$\begin{array}{c}\text { Choice of sedative } \\
\text { medications }\end{array}$} & \multirow{2}{*}{$\begin{array}{l}\text { Total } \\
\text { cases } \\
(\mathrm{n}=547)\end{array}$} & \multirow[t]{2}{*}{$\begin{array}{l}\text { Median initial dose }{ }^{\dagger} \\
\text { (range), mg }\end{array}$} & \multicolumn{2}{|c|}{$\begin{array}{c}\text { Route of } \\
\text { administration, } \mathbf{n}(\%)\end{array}$} \\
\hline & & & $\begin{array}{c}\text { IV } \\
(n=110)\end{array}$ & $\begin{array}{c}\text { IM } \\
(n=437)\end{array}$ \\
\hline Monotherapy & $472(86.3)$ & - & $82(74.5)$ & $390(89.2)$ \\
\hline droperidol & $381(69.7)$ & $10(1-30)$ & $38(34.6)$ & $343(78.5)$ \\
\hline midazolam & $54(9.9)$ & $5(1-10)$ & $38(34.5)$ & $16(3.7)$ \\
\hline olanzapine & $26(4.8)$ & $10(2.5-10)$ & $0(0.0)$ & $26(5.9)$ \\
\hline haloperidol & $5(0.9)$ & $2.5(2-10)$ & $1(0.9)$ & $4(0.9)$ \\
\hline diazepam & $4(0.7)$ & $7.5(2.5-10)$ & $2(1.8)$ & $2(0.5)$ \\
\hline lorazepam & $1(0.2)$ & $2^{*}$ & $0(0.0)$ & $1(0.2)$ \\
\hline propofol & $1(0.2)$ & $70^{*}$ & $1(0.9)$ & $0(0.0)$ \\
\hline Combination therapy & $75(13.7)$ & - & $28(25.5)$ & $47(10.8)$ \\
\hline droperidol + midazolam & $36(6.6)$ & $10(2.5-20)+5(2-10)$ & $13(11.8)$ & $23(5.3)$ \\
\hline olanzapine + midazolam & $9(1.6)$ & $10(5-10)+5(2-10)$ & $1(0.9)$ & $8(1.8)$ \\
\hline droperidol + olanzapine & $8(1.5)$ & $10+10^{*}$ & $0(0.0)$ & $8(1.8)$ \\
\hline droperidol + diazepam & $6(1.1)$ & $7.5(5-10)+7.5(5-10)$ & $3(2.7)$ & $3(0.7)$ \\
\hline haloperidol + midazolam & $5(0.9)$ & $20(2.5-20)+5(1-10)$ & $4(3.6)$ & $1(0.2)$ \\
\hline droperidol + ketamine & $3(0.5)$ & $10(10-20)+200(30-200)$ & $1(0.9)$ & $2(0.5)$ \\
\hline ketamine + midazolam & $3(0.5)$ & $60(40-150)+5(5-10)$ & $3(2.7)$ & $0(0.0)$ \\
\hline droperidol + clonazepam & $2(0.4)$ & $4.75(2-7.5)+2.25(0.5-4)$ & $2(1.8)$ & $0(0.0)$ \\
\hline droperidol + lorazepam & $1(0.2)$ & $10+2^{*}$ & $0(0.0)$ & $1(0.2)$ \\
\hline ketamine + clonazepam & $1(0.2)$ & $400+4^{*}$ & $0(0.0)$ & $1(0.2)$ \\
\hline
\end{tabular}




$\begin{array}{llll}\text { ketamine }+ \text { morphine } & 1(0.2) & 10+1^{*} & 1(0.9)\end{array}$

$\mathrm{IV}=$ intravenous; $\mathrm{IM}=$ intramuscular

$\dagger$ This was the total initial dose and may have been administered incrementally over the first 15 minutes.

* This was the actual dose administered to the patient, no other dose was observed.

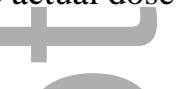

Table 3. Frequency and nature of adverse events across all study sites

\section{Respiratory AEs}

Oxygen desaturation

Airway obstruction

Hypoventilation

\section{Cardiovascular AEs}

Bradycardia

Hypotension

Prolonged QTc

Tachycardia

$1(0.2)$

\section{Others}

EPSE

Vomiting

Urinary retention

Dry mouth

Fall

Anaphylaxis 
$\mathrm{AE}=$ adverse event; $\mathrm{EPSE}=$ extrapyramidal side effects; $\mathrm{QTc}=$ corrected $\mathrm{QT}$ interval

Table 4. Initial choice of sedation regimens for patients aged $>65$ years

\begin{tabular}{|c|c|c|c|c|}
\hline \multirow{2}{*}{$\begin{array}{l}\text { Choice of sedative } \\
\text { medications }\end{array}$} & \multirow{2}{*}{$\begin{array}{l}\text { Total } \\
\text { cases } \\
(n=31)\end{array}$} & \multirow{2}{*}{$\begin{array}{l}\text { Median initial dose } \\
\quad(\text { range })^{\dagger}, \mathrm{mg}\end{array}$} & \multicolumn{2}{|c|}{ Route of administration, $\mathrm{n}(\%)$} \\
\hline & & & IV $(n=15)$ & IM $(n=16)$ \\
\hline Monotherapy & $28(90.3)$ & - & $13(86.6)$ & $15(93.8)$ \\
\hline droperidol & $15(48.4)$ & $5(2.5-15.0)$ & $2(13.3)$ & $13(81.3)$ \\
\hline olanzapine & $5(16.1)$ & $5(2.5-10.0)$ & $5(33.3)$ & $0(0.0)$ \\
\hline midazolam & $5(16.1)$ & $2(1.0-3.0)$ & $5(33.3)$ & $0(0.0)$ \\
\hline haloperidol & $3(9.7)$ & $2.5(2.0-5.0)$ & $1(6.7)$ & $2(12.5)$ \\
\hline Combination therapy & $3(9.7)$ & - & $2(13.4)$ & $1(6.2)$ \\
\hline droperidol + midazolam & $1(3.2)$ & $10+10$ & $0(0.0)$ & $1(6.2)$ \\
\hline droperidol + clonazepam & $1(3.2)$ & $2+0.5$ & $1(13.4)$ & $0(0.0)$ \\
\hline haloperidol + midazolam & $1(3.2)$ & $2.5+1$ & $1(13.4)$ & $0(0.0)$ \\
\hline $\begin{array}{l}\text { IV = intravenous; } \mathrm{IM}=\text { intram } \\
\dagger \text { This was the total initial do }\end{array}$ & dd may hav & en administered incre & lly over the fir & inutes. \\
\hline
\end{tabular}

1. Gilchrist H, Jones SC, Barrie L. Experiences of emergency department staff: Alcoholrelated and other violence and aggression. Australasian emergency nursing journal. 2011;14(1):9-16.

2. Shradha N, Alexander O, Evan S, Robert G, Gerard OR, Biswadev M. Increasing workplace violence in an Australian adult emergency department. Emerg Med Australas.

2018;30(2):181-6.

This article is protected by copyright. All rights reserved 
3. National Institute for Health and Care Excellence (NICE). Violence and aggression: shortterm management in mental health, health and community settings: NICE Guideline [NG10] 2015; [Accessed. Available from: https://www.nice.org.uk/guidance/ng10/evidence/fullguideline-pdf-70830253.

4. Behavioural emergencies. Electronic Therapeutic Guidelines Complete. 2013 [cited 11/7/2018].In: Psychotropic [Internet]. Melbourne: Therapeutic Guidelines Limited, [cited 11/7/2018]. Available from: https://tgldcdp-tg-orgau.ezproxy.lib.monash.edu.au/viewTopic?topicfile=behavioural-emergencies .

5. Kotaro Hatta, Toshitaka Kawabata, Kenichi Yoshida, Hiroshi Hamakawa, Toru Wakejima, Ko Furuta, et al. Olanzapine orally disintegrating tablet vs. risperidone oral solution in the treatment of acutely agitated psychotic patients. Gen Hosp Psychiat. 2008;30(4):367-71.

6. Battaglia J. Pharmacological management of acute agitation. Drugs. 2005;65(9):1207-22.

7. Taylor DM, Yap CYL, Knott JC, Taylor SE, Phillips GA, Karro J, et al. MidazolamDroperidol, Droperidol, or Olanzapine for Acute Agitation: A Randomized Clinical Trial. Ann Emerg Med. 2017;69(3):318-26.e1.

8. Korczak V, Kirby A, Gunja N. Chemical agents for the sedation of agitated patients in the ED: a systematic review. Am J Emerg Med. 2016;34(12):2426-31.

9. Chan EW, Taylor DM, Knott JC, Phillips GA, Castle DJ, Kong DC. Intravenous droperidol or olanzapine as an adjunct to midazolam for the acutely agitated patient: a multicenter, randomized, double-blind, placebo-controlled clinical trial. Ann Emerg Med. 2013;61(1):7281.

10. Riddell J, Tran A, Bengiamin R, Hendey GW, Armenian P. Ketamine as a first-line treatment for severely agitated emergency department patients. The American Journal of Emergency Medicine. 2017;35(7):1000-4.

11. Zun LS. Evidence-Based Review of Pharmacotherapy for Acute Agitation. Part 2: Safety. The Journal of Emergency Medicine. 2018.

12. Knott JC, Taylor DM, Castle DJ. Randomized Clinical Trial Comparing Intravenous Midazolam and Droperidol for Sedation of the Acutely Agitated Patient in the Emergency Department. Ann Emerg Med. 2006;47(1):61-7.

13. Ferreira PM, Guerra C, Silva A. Psychomotor agitation in a psychiatric emergency service. Eur Psychiatry. 2013;28. 
14. Bervoets C, Roelant E, De Fruyt J, Demunter H, Dekeyser B, Vandenbussche L, et al. Prescribing preferences in rapid tranquillisation: a survey in Belgian psychiatrists and emergency physicians. BMC Res Notes. 2015;8(1):1-8.

15. Chan EWY, Tang C, Lao KSJ, Ling Pong L, Tsui MSH, Ho HF, et al. Management of acute agitation in Hong Kong and comparisons with Australasia. Emerg Med Australas. 2015;27(6):542-8.

16. Martel M, Miner J, Fringer R, Sufka K, Miamen A, Ho J, et al. Discontinuation of droperidol for the control of acutely agitated out-of-hospital patients. Prehosp Emerg Care. $2005 ; 9(1): 44-8$.

17. Chan EW, Taylor DM, Knott JC, Kong DC. Variation in the management of hypothetical cases of acute agitation in Australasian emergency departments. Emerg Med Australas. 2011;23(1):23-32.

18. Yap CYL, Taylor DM, Knott JC, Taylor SE, Phillips GA, Karro J, et al. Intravenous midazolam-droperidol combination, droperidol or olanzapine monotherapy for methamphetamine-related acute agitation: subgroup analysis of a randomized controlled trial. Addiction. 2017; 112:1262-9.

19. Calver L, Page CB, Downes MA, Chan B, Kinnear F, Wheatley L, et al. The Safety and Effectiveness of Droperidol for Sedation of Acute Behavioral Disturbance in the Emergency Department. Ann Emerg Med. 2015;66(3).

20. Ministry of Health NSW. Management of patients with acute severe behavioural disturbance in emergency department guidelines; 2015; [Accessed 2/8/2017]. Available from: http://www1.health.nsw.gov.au/pds/ActivePDSDocuments/GL2015_007.pdf.

21. Queensland Health. Management of patients with Acute Severe Behavioural Disturbance in Emergency Departments 2015; [Accessed 10/7/2018]. Available from: https://www.health.qld.gov.au/_data/assets/pdf_file/0031/629491/qh-gdl-438.pdf.

22. Isbister GK, Calver LA, Page CB, Stokes B, Bryant JL, Downes MA. Randomized Controlled Trial of Intramuscular Droperidol Versus Midazolam for Violence and Acute Behavioral Disturbance: The DORM Study. Ann Emerg Med. 2010;56(4):392-401.

23. Calver L, Isbister GK. Parenteral sedation of elderly patients with acute behavioral disturbance in the ED. Am J Emerg Med. 2013;31(6):970-3.

24. Australian Medicines Handbook Adelaide: Australian Medicines Handbook Pty Ltd; 2018. 
25. Simpkins D, Peisah C, Boyatzis I. Behavioral emergency in the elderly: a descriptive study of patients referred to an Aggression Response Team in an acute hospital. Clin Interv Aging. 2016; 11:1559-65.

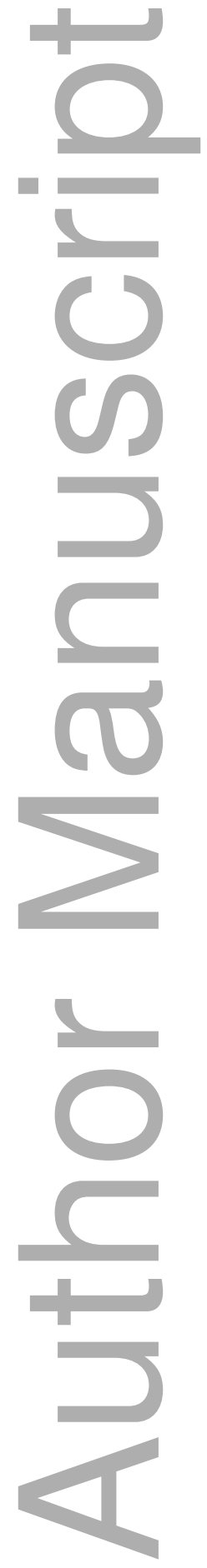




\section{University Library}

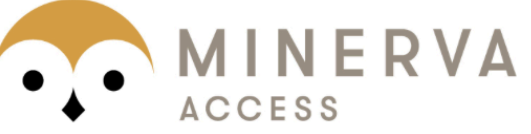

A gateway to Melbourne's research publications

Minerva Access is the Institutional Repository of The University of Melbourne

Author/s:

Yap, CYL;Taylor, DMD;Kong, DCM;Knott, JC;Taylor, SE;Graudins, A;Keijzers,

G;Kulawickrama, S;Thom, O;Lawton, L;Furyk, J;Finucci, D;Holdgate, A;Watkins, G;Jordan, P

Title:

Management of behavioural emergencies: a prospective observational study in Australian emergency departments

Date:

2019-08-01

Citation:

Yap, C. Y. L., Taylor, D. M. D., Kong, D. C. M., Knott, J. C., Taylor, S. E., Graudins, A., Keijzers, G., Kulawickrama, S., Thom, O., Lawton, L., Furyk, J., Finucci, D., Holdgate, A., Watkins, G. \& Jordan, P. (2019). Management of behavioural emergencies: a prospective observational study in Australian emergency departments. Journal of Pharmacy Practice and Research, 49 (4), pp.341-348. https://doi.org/10.1002/jppr. 1522.

Persistent Link:

http://hdl.handle.net/11343/286132 